\title{
ERIC HEYNE
}

\section{Truth or Consequences: Individuality, Reference, and the Fiction/Nonfiction Distinction}

\begin{abstract}
Theories of the fiction/nonfiction distinction generally choose one particular measure of referentiality on which to ground their divisions. Thus nonfiction has been variously distinguished from fiction by authorial intention, genre conventions, or the ontological status of the text. However, not even the most reasonable and straightforward of such measures has compelled widespread agreement among critics on a clear-cut border. The complex reality of how humans use narrative to model experience suggests that no single formula will ever explain how different readers experience different texts, either in the moment of their consumption or afterwards in the construction of readers' views of reality. The web of ways we use narrative conventions - and are ourselves constituted by those conventions - suggests that we need to develop a more subtle and complex theory of fiction and nonfiction, and abandon the beautiful dream of a simple sorting machine.
\end{abstract}

Most theories of the fiction/nonfiction distinction are verbal formulae for measuring some kind of referentiality, sorting machines based on one of several possible axes of division. The appeal of such a formula is undeniable. We all routinely distinguish among fiction and nonfiction, truth and lies, myth and history, to name only three of the most familiar binaries, and so we naturally assume there is a handy method that we employ for doing so. All we have to do is figure out which algorithm we use to make the distinction, and since we do it so often and so easily, we conclude that the algorithm must be fairly simple also, a clean blade with which we routinely slice our way through the thicket of narrative.

Thus, one theory, using authorial intention as its blade, will sort texts according to the narrative conventions declared by the author to be appropriate. Such an authorial declaration might be made via any of several routes: completely outside the text, in interviews, marketing campaigns, and the like; in paratextual locations such as subtitle, acknowledgments, disclaimer, or notes; explicitly in the narrative text itself, with claims about 'the truth' or 'the facts'; or implicitly in the text, by the choice of particular techniques such as internal monologue or exact quotation. Perhaps the most influential proponent of this algorithm was John Searle, who argued in "The Logical Status of Fictional Discourse" for his speech-act theory 
approach employing a simple binary distinction based on "the illocutionary intentions of the author" (Searle 1975, 325). ${ }^{1}$

Another theory, using broad cultural conventions as its sorting mechanism, divides narratives according to their adherence to or violations of accepted practices of history, journalism, and fiction. The strongest proponents of this approach tend to be journalists or historians defending their turf by insisting upon the sacredness of their methods. Hence the journalist-turned-literary-theorist Daniel $\mathrm{H}$. Lehman argued in Matters of Fact: Reading Nonfiction over the Edge for a "dialectical edge" that divides fiction and nonfiction, the latter determined by "the materiality of its referents" (Lehman 1997, 37 and 39). That "materiality" can only be measured by adherence to or violation of the conventions of journalism and history, the rules of verifiability, the limitations of eyewitness and exact quotation. ${ }^{2}$ In order to avoid a naïve theory of reference, Lehman (and the majority of practicing journalists and historians) depends on a set of rules of reference. What violates those rules is not nonfiction; by default, then, it usually becomes fiction. Although this approach may look quite similar to one based on authorial intention when that intention is to choose among different conventions, the focus is on the conventions themselves, with the author's intentions being ultimately irrelevant. That is, it doesn't matter whether you intended to tell the truth or embellish it, only whether you followed the rules.

Journalists and historians are not the only people who use cultural conventions as their method of sorting fiction from nonfiction. In recent years narratologists exploring the conventional practices of fiction have arrived at the same methodology. In The Distinction of Fiction Dorrit Cohn is particularly interested in how authors of fiction have played with some of the methods of nonfiction; her working distinction comes down to nonfiction being "referential," which in turn depends on its being "verifiable" according to our cultural epistemological practices (Cohn 1999, 16). ${ }^{3}$

Yet a third way of distinguishing fiction and nonfiction focuses primarily on the reader rather than the author or the culture. Marie-Laure Ryan acknowledges that "[a] definition of fiction is a machine built for the purpose of telling fiction from nonfiction" (Ryan 1991, 80), and her particular machine operates according to the principles of possible worlds theory. The essential question is, once again, reference or correspondence, but this time correspondence between the worlds of text and reader. Such correspondence may take a variety of forms, and Ryan produces an impressive grid of genres based on ten different ways in which the

1 My own earlier work in this area is very much influenced by Searle, especially "Toward a Theory of Literary Nonfiction" (Heyne 1987). In fact, I have been taken to task by Daniel W. Lehman for my overly simplistic author-centered approach (1997, 19-21).

2 Although Lehman explicitly denies that he is advocating for a single-factor method of distinguishing fiction and nonfiction, and although he claims that "the boundary is never absolute" $(1997,24)$, I believe that his applied criticism nevertheless operates with the kind of sorting mechanism I am ascribing to him.

3 Cohn modifies this in the course of her book to "bi-referential" vs. "tri-referential," but this adjustment does not fundamentally change her characterization of the fiction/nonfiction distinction. 
worlds of text and reader may match precisely, be compatible, or diverge. This grid allows her to distinguish among what she calls "[a]ccurate nonfiction," " $\mathrm{t}]$ rue fiction," and "[r]ealistic and historical fiction," among other categories.

A more pragmatic version of a reader-centered theory of the fiction/nonfiction distinction focuses, not on correspondence between the worlds of reader and text, but on how the reader chooses to use the text. That is, a narrative is fiction if it is used as fiction, which generally means read for pleasure, for the purposes of being absorbed in the story. If the reader pays more attention to reference, however, looking for and testing connections between story and her view of reality, then the text is being used as nonfiction. Thus a reader interested in the life of Hemingway might comb one of his novels for biographical clues, while, as Thomas Pavel claims, someone else might read "well-written memoirs or romanced biographies," for example, "fictionally for purely textual reasons" (Pavel 1986, 71). As Pavel's observation points out, however, this pragmatic approach achieves its greater flexibility at the cost of any correspondence with conventional genre boundaries. But that high price may turn out to be worth paying, as I will suggest in a moment.

A fourth and final method of sorting fiction from nonfiction is entirely textually based, rooted in the ontological status of the text itself. Such theories, while they might differ as widely in their particular approach as Mas'ud Zavarzadeh's "angle of reference" and Barbara Herrnstein Smith's "fictive" and "natural utterances," have collectively been the least influential, and have been sufficiently discredited by subsequent critics. But they are worth noting here because they represent a logically satisfying fourth branch - adding text to the triad of author, world, and reader - of the broad inquiry I am characterizing as the search for a simple sorting machine. ${ }^{4}$

I want to begin making my case against the usefulness of that search by returning to the role of the reader. Many critics with widely different theories have acknowledged the pragmatic dimension of reading - that texts can be 'taken' in a variety of ways, some very different from either what their authors intended or how the majority of readers 'take' those texts. ${ }^{5}$ But I do not think enough attention has been paid to the complex implications of this pragmatic dimension for describing how we read. Many versions of the fiction/nonfiction distinction employ a spatial metaphor to describe the difference in reading experience, something like inside/ outside. One reason this metaphor appeals to us is because of the phenomenon that Victor Nell has explored in Lost in a Book: The Psychology of Reading for Pleasure. Our most intense reading experiences create a sense of entering a separate world, cooperating with the text in the evocation of a story-reality that temporarily diverts our attention from our surroundings. Nell uses the metaphors of play, eating,

4 There is of course one more logical position available in the grid I have outlined: that there is no difference between fiction and nonfiction. I suspect this position is more widely avowed than actually believed, but in any event I will address this view below.

5 Including not only Pavel, but also (among the critics I have mentioned thus far) Ryan (1991, 76-8), Cohn (1999, 159ff.), and Lehman (1997, in his various accounts of "reading against the grain"). 
trance, and enchantment, among others, to explore what he calls "reading sovereignty," the sense of entering another domain, being elsewhere, giving over (at least partial) control to a story.

The next logical question is, can this phenomenon be used to distinguish between fiction and nonfiction? Nell thinks so, claiming that the experience of reading fiction (or "companion books") is different than that of reading nonfiction (or "utensil books") because while reading fiction "we can willingly suspend our realitytesting feedback processes" (Nell 1988, 142 and 56). Many narrative theorists who have adopted this inside/outside approach have done so as part of their attempt to characterize the literary experience, adopting what Ruth Ronen has called "hermeticist claims about the literary text" (Ronen 1994, 21). Northrop Frye's influential "inward" and "outward" distinction in Anatomy of Criticism even collapsed the terms "fiction" and "literature," and later critics such as John Hellman and W. Ross Winterowd have adapted Frye's model. Good stories draw us in, engage our attention, create satisfying and apparently discrete experiences, and because for many readers the most powerful of such stories are literary fiction, it seems natural to characterize such experience as the measure of literariness or fictionality. ${ }^{7}$

However, it is obvious that: 1) not all literature is absorbing; 2) much of the most absorbing reading (including many of Nell's "companion books") is not literary (at least in the honorific sense of that term); 3) some true stories are quite absorbing to some readers; and, most importantly for my inquiry, 4) different readers may be more or less absorbed in the same text, and for different reasons. We cannot, in the end, base a definition of fiction on the experience of being absorbed, unless we allow that fictionality varies radically from reader to reader. ${ }^{8}$

But what if it does? What if some readers treat a story as fiction and other readers treat the same story as nonfiction? Clearly this happens sometimes, not only with the obvious example of religious mythology, but also with narratives of less cosmic significance, such as Truman Capote's In Cold Blood, Oliver Stone's JFK, Susan Orlean's The Orchid Thief, and certain official U.S. government reports regarding the presence of weapons of mass destruction in pre-war Iraq. In my own research I have most often addressed this issue in connection with In Cold Blood,

6 Frye's use of the term "fiction" as synonymous with "literary" is so extreme that for him fictionality does not even imply narrative status - it can be used to describe lyric poems, for instance.

7 There are any number of competing notions of literature and literariness, of course, but I am going to do my level best in this essay to keep a lid on that particular can of worms.

8 The most fascinating recent version of this view that literature creates a characteristic experience is Vladimir E. Alexandrov's "Literature, Literariness, and the Brain," in which he surveys positron emission topography and functional magnetic resonance imaging studies for evidence to support Roman Jakobson's forty-seven-year-old definition of literariness. While this hi-tech approach allows Alexandrov to make "several broad, albeit tentative, generalizations about language processing in relation to hemispheric specialization and cooperation" (Alexandrov $2007,112-3$ ), even he admits that much more work needs to be done before we can begin to talk about isolating and measuring "literariness" in the brain. 
because that text seems to elicit a wide range of categorizations from trained readers (i.e., my colleagues). Smart, perceptive critics do not agree, as far as I can determine from a twenty-year informal survey, on the fictional or nonfictional status of that book. Is it because they do not agree on what constitutes fiction and nonfiction?

Certainly there is some disagreement over that question - otherwise how could there be so many competing theories, including the sampling I have cited in this essay? But I want to suggest another reason for this variety, one that presumes not a range of firmly set boundaries, each upheld by a particular reader, but rather a more fluid and ad hoc borderland, one that varies by reader, by text, and even by changed circumstances (with the same reader and text). That is, I believe we treat texts as fiction or nonfiction based on a complex web of factors, any of which can change over time, even relatively short stretches of time when our functional relationship to a text has changed. Most of the time most of our uses of most of our texts are stable. We do not routinely decide that today's paper is nonfiction, and then tomorrow that it was fiction after all. But we do sometimes, more often than we recognize, and not merely with deliberately experimental narratives like In Cold Blood, change our minds. And sometimes when we do so it feels like the text itself has changed, because the relationship between reader and narrative is so often remarkably complex and fluid.

Let me begin unfolding that relationship with an observation Cohn makes in discussing historical fiction:

What is certain is that an individual's reaction to [historical novels] is conditioned by the degree to which the historical material concerned touches on his or her values and sensitivities. When I recently learned certain biographical facts about the desert explorer Laszlo Almasy, for example, my initial admiration for Michael Ondaatje's novel The English Patient (in which Almasy figures as the titular character) dropped down a few notches. There is, it seems, documentation to show that Almasy was an opportunist and highly nefarious Nazi collaborator, not (as the novel shows him) a semi-innocent victim of the ruthless German army. By contrast, my high estimation of Coetzee's The Master of Petersburg was not in the least dislodged when I found out that Dostoevsky's stepson Pavel, whose death Coetzee's Dostoevsky mourns throughout the novel, in fact survived him by several years. All this goes to show that, though distortions of known facts in a historical novel may only occasionally detract from our value judgment, we do tend to approach this genre differently from other novelistic genres. (Cohn 1999, 159)

Cohn uses this observation to help her distinguish historical fiction from other fiction, but certainly not to question what she calls "the essential separation of the historical novel from historical narrative" (Cohn 1999, 157). However, I think her personal reading revelation does point to a greater flexibility or variability in how we read. I would extend Cohn's observation to the claim that whether we regard a text as fiction or nonfiction sometimes depends on our particular "values and sensitivities," as well as on how much contextual information we have about a narrative and what our stake is in any particular version of that narrative. With nothing at stake except our reading experience itself, we will default to a fictional mode. That is, we treat a story as nonfiction when we have some reason to do so, and as fiction, simply a "good story," when we have no reason to do otherwise. 
For help in understanding how such an important and frequently employed distinction as that between fiction and nonfiction could nevertheless be so dependent on a variety of variables I would turn to A. P. Martinich and Avrum Stroll's Much Ado About Nonexistence: Fiction and Reference. Their most important point for the purposes of my inquiry is the observation that we use the same language with equal facility to refer to real and fictional things. Facts do not necessarily depend on material existence: "In ordinary life, persons frequently speak meaningfully about that which does not exist" (Martinich / Stroll 2007, 106). It is a fact that Sherlock Holmes lived in London, for instance, and anyone who claimed that he lived in Bangkok would have to construct a convincing argument for that claim - even if we agree that Holmes never existed. Many of the salient facts on which people construct their lives, for that matter, are based on little or no empirical evidence, or held by individuals who do not make any effort to determine if such evidence actually exists, facts such as the existence of God, the corruption of the Republic Party, the lack of potential dating partners in New York City, the true nature of various celebrities, and the CIA/FBI conspiracy to assassinate JFK. Many of our references to 'the real world' or (as often used in possible worlds theory) 'the actual world' are to abstractions, inventions, fictions, and other useful human creations. As Martinich and Stroll observe in talking about the status of "legal fictions" (which are actually legal facts counter to normal inference), "[p] hilosophers may protest that these alleged facts are not facts, but that is only because they want to acknowledge only physical facts as facts, when the world as lived and experienced by human beings is more complex, more enjoyable, and philosophically fun" (Martinich / Stroll 2007, 38). ${ }^{9}$

When we move from philosophy to cognitive narrative theory, we add an additional complication to the question of reference and reality. I agree with Jerome Bruner that narrative is a particular mode of cognition:

A good story and a well-formed argument are different natural kinds. Both can be used as means for convincing another. Yet what they convince of is fundamentally different: arguments convince one of their truth, stories of their lifelikeness. The one verifies by eventual appeal to procedures for establishing formal and empirical proof. The other establishes not truth but verisimilitude. (Bruner 1986, 11; emphasis in the text)

"Verisimilitude" is very like truth, or may even be a kind of truthfulness. ${ }^{10}$ Some critics have in fact distinguished between the "factual truth" of nonfiction narrative and the mere "verisimilitude" of fiction. But I have come to believe that we do not carefully make much distinction between those two kinds of truth. Rather, we adapt our lives based on what we perceive to be lived or experiential truth,

9 For another brief and very engaging philosophical take on the question of "real feelings about things known not to exist" (Martinich and Stroll 2007, 39), see Ted Cohen's Presidential Address to the Central Division of the American Philosophical Association, entitled "Stories." Roger C. Schank goes even farther than Bruner in his argument that "[s]torytelling and understanding are fundamentally the same thing" (Schank 1990,24), that, as one of his chapter titles has it, "Knowledge Is Stories." Schank's claims about memory and "scripts" based on stories are challenging and fascinating, but I am not yet ready to go quite so far down the path of narrative omnipresence. 
which can have any number of different connections to fact, evidence, and 'the real world.' Hearing the story of an adulterous affair carried on by one of our acquaintances may or may not lead us to adjust our view of the world significantly (although it probably occasions at least a few small, specific adjustments); but reading John Updike's novel Couples may also lead to such a shift in our beliefs (and may even bring about small, specific adjustments to our views of certain acquaintances). One story is fact and the other fiction, but we may use those stories in virtually identical ways - and that, in the crux of my argument in this essay, means that we may never be able confidently or easily to distinguish between fiction and nonfiction.

Note that apart from passing references, I have not so far in this essay focused the discussion on borderline cases, problematic narratives, or genre-blurring texts. I am fascinated by such works, and very much appreciate the applied criticism of not only Hellman, Cohn, and Lehman, but also Barbara Foley, Phyllis Frus, Chris Anderson, Shelley Fisher Fishkin, and Ronald Weber. ${ }^{11}$ 'Nonfiction novels,' 'true-life fiction,' 'documentary novels,' and other such experiments can help us sharpen our sense of how we read, as well as change the way we think about knowledge itself. But if the claims I am making here about the radical flexibility of the fiction/nonfiction distinction have any force, it will be because they work for a wider range of texts than just the deliberately difficult. In order for me to be right, it must be the case that all sorts of stories, from oral anecdotes to newspaper articles and 'regular' novels, affect our sense of the world in complex, messy ways, depending on individual variables in both text and reader. A book like In Cold Blood can help bring such variables into sharper relief, because careful readers have arrived at different conclusions about the same well-crafted text. But the dynamics are the same for much less interesting stories, and sometimes the variables involved will produce the same kind of disjunctive readings.

An obvious question at this point is, why not simply give up on the whole enterprise of distinguishing fiction and nonfiction? Why not just adopt, with E. L. Doctorow, "the proposition that there is no fiction or nonfiction as we commonly understand the distinction: there is only narrative" (Doctorow 1977, 231)? Or as Michael Pearson has put it, "does it make a difference if we make our stories out of facts or fictions any more than it matters if a sculptor makes a statue out of marble or clay?" (Pearson 2005, 366). One obvious answer to that question is, we should maintain the usefulness of separating fiction from nonfiction as long as we routinely continue to do so in such a wide variety of environments as college curricula, courts of law, bookstores, and office gossip. If fiction and nonfiction are related to each other in the sort of default and marked-case way that I have asserted, it is easy to see why some novelists might want to erode the distinction, since they could thereby attain some of the extra authority attached to nonfiction without

11 Weber's book in particular is a good illustration of how a perceptive critic can say very useful things about a wide variety of experimental or borderline texts without feeling the need for any particular theoretical framework. Since he does not have to support a scaffolding of theory, Weber never has to resist the temptation to stretch a point, over-generalize, or ignore counterevidence. 
having to abide by the rules for qualifying for such authority. And it is equally easy to imagine some practitioners of 'creative nonfiction' looking for ways to 'improve' their stories without having to forfeit the authority of nonfictional status. ${ }^{12}$ Eschewing such cynicism, however, we can still understand why, if I am right about the complex nature of the fiction/nonfiction distinction, many writers who have had a more or less explicit awareness of that complexity through their working knowledge of writing narrative might decide that no boundary is better than a too-rigid or too-simple boundary. But the vast majority of narrative writers, by my count, are dedicated to maintaining that boundary even in the face of its maddening and encouraging flexibility. In "The Creative Nonfiction Police," Lee Gutkind (founder of the journal Creative Nonfiction) lays out some of the methods by which "that thin, blurred line between fiction and nonfiction" (Gutkind 2005, 350) can be respected or violated. He concludes with a call to writers to "strive for the truth" (353), which he takes to be an important ethical decision, but one that all writers face, including authors of lyric poetry and short stories as well as journalism. Even after posing that clever question about whether narrative is like sculpture, Pearson nevertheless claims that literary nonfiction "has one sacred principle: you can't make it up" (Pearson 2005, 367). For every narrative provocateur like Doctorow, there are a hundred writers working the frontier between fiction and nonfiction who agree with John Hersey that " $[\mathrm{t}]$ he legend on the license must read: NONE OF THIS WAS MADE UP" (Hersey 1980, 2; emphasis in the text) - even as they eagerly explore the question of what "making it up" means. ${ }^{13}$

In searching for a not-too-rigid and not-too-simple way to talk about this distinction that we are apparently not at all ready to give up, I am powerfully drawn to possible worlds theory, because it does justice to our sense that stories are worlds, versions, models of human experience. They are able to take on some kind of reality or presence beyond their status as language, becoming, as James Phelan has characterized them, "worlds with potentially inexhaustible resources" (Phelan 1981, 231). In reading or listening to stories we construct scenarios, posit circumstances, and plug in our own experience to flesh out the details we are provided. This is one explanation for why talking on the phone while driving is so dangerous, even hands-free talking, and even when compared to in-car conversations and other distractions. While carrying on a phone conversation we are positing a separate reality, participating in the construction of an alternative world, imagining ourselves elsewhere, something like what we do when we read narrative. The result

12 Perhaps the most famous formulation of this particular urge comes from historian Hayden White, who has taken all of historiography to task for its will to fiction, as it were, its "desire to have real events display the coherence, integrity, fullness, and closure of an image of life that is and can only be imaginary" (White 1987, 24).

13 There is an incredible wealth of what we might call "applied reflection" on the fiction/nonfiction distinction available in the literature of "creative nonfiction." For instance, Patricia Hampl has brilliantly explored the narrative consequences of the fact that "memory inevitably leads to invention" (Hampl 1999, 27). Such inquiries constitute their own sub-field, at once practical and theoretical, currently the province of teachers and students in creative writing programs, but potentially of great use to literary theorists. 
may be an accident attributed to "inattention blindness." ${ }^{\text {"14 }}$ Maintaining the necessary level of concentration on dual realities, those of the driving world and the phone world, is genuinely difficult. We can inhabit two (or more?) worlds at a time, but it is impossible to maintain full attention in both. (Think about getting the attention of a child watching television or a teen playing a video game.) Part of the appeal of stories is precisely their ability to take our attention elsewhere, to conjure up for us alternative worlds.

But just as I have questioned the utility of defining fiction merely by gauging its ability to command our attention, so I question the tendency in possible worlds theory to make neat distinctions between worlds. It is not entirely fair, but my most salient image of possible worlds theory as applied to literature is taken from set theory as learned in ninth-grade geometry class: line drawings of different-sized circles, some overlapping, some not, labeled 'reader' and 'text' and 'actual world.' Ryan's impressive schemata, employing the neat binary notation of $+/-$, is another instance of how possible worlds theory can seduce us with its appeal to clarity, simplicity, and mathematical precision. Luckily, such spurious precision does not characterize all possible world approaches; certainly it is possible (as Ryan's own applied criticism often demonstrates) to use the idea of alternate worlds in ways that do justice to what Pavel calls "the deep heterogeneity of texts" (Pavel 1986, 71).

One way to maintain our awareness of that "heterogeneity" is by attention to the psychological and cognitive components of the text-reader equation. We are by some accounts built up of texts ourselves, and reading is a process of augmenting that text-self with stories, both true and made-up. Bruner's advice is to "think of Self as a text about how one is situated with respect to others and toward the world - a canonical text about powers and skills and dispositions that change as one's situation changes from young to old, from one kind of setting to another" (Bruner 1986, 130). Donald P. Spence, in exploring the reconstruction of self through stories that takes place in psychoanalysis, points out the "almost embarrassing flexibility of narrative," which because of its "loose syntax" of "and then ... and then ... and then ..." "is almost infinitely elastic" (Spence 1982, 182). This means that we can easily adapt our narratives of self to make our stories more coherent, and the struggle (or perhaps dance) between "narrative truth" and "historical truth" can pose "a serious problem" for the psychoanalyst (Spence 1982, 183). As it can, I would suggest, for the literary analyst. If our very psyches are so porous and susceptible to story regardless of factuality, how can we expect it to be easy for us to sort fiction from nonfiction in the wealth of texts to which we expose those psyches? In exploring the concept of narrative empathy, Suzanne Keene suggests that "readers' perception of a text's fictionality plays a role in subsequent empathic response, by releasing readers from the obligations of self-protection through skepticism and suspicion" (Keene 2006, 220). Keene's research is an excellent example of how

14 See for instance (to take just the first hit from a Google search) the results of a recent University of Utah study by David L. Strayer, Frank A. Drews, and Dennis J. Crouch, "A Comparison of the Cell Phone Driver and the Drunk Driver," published in Human Factors: The Journal of the Human Factors and Ergonomics Society 48 (2006), 381-91. 
a cognitive approach can acknowledge the complex interplay between authorial intention, narrative technique, narrative conventions, and readers' individuality.

As useful as I find possible worlds theory and cognitive narrative theory for helping me think about the fiction/nonfiction distinction, obviously I am not going to conclude with my own particular Unified Field Theory of Narrative. To do so would be to go against everything I have been arguing in this essay. Quite the contrary, I want to conclude by qualifying my remarks about the range of approaches I surveyed early on. Every critic I have cited has demonstrated a sophisticated and complex understanding of the fiction/nonfiction distinction, and my brief citations and pigeonholing have obviously not done justice to that understanding. But I cannot help feeling that an awful lot of work in this area has been wasted on the dream of a simple sorting machine. By letting go of that dream, we may be able to progress farther and faster in our understanding of why the truth of stories matters to us, and when it doesn't.

\section{Works Cited}

Alexandrov, Vladimir E. (2007). "Literature, Literariness, and the Brain." Comparative Literature 59.2, 97-118.

Anderson, Chris (1987). Style as Argument: Contemporary American Nonfiction. Carbondale, IL: Southern Illinois University Press.

Bruner, Jerome (1986). Actual Minds, Possible Worlds. Cambridge, MA: Harvard University Press.

Cohen, Ted (2007). "Stories." Proceedings and Addresses of the American Philosophical Association 81:2, 33-48.

Cohn, Dorrit (1999). The Distinction of Fiction. Baltimore, MD: Johns Hopkins University Press.

Doctorow, E.L. (1977). "False Documents." American Review 26, 215-32.

Fishkin, Shelley Fisher (1985). From Fact to Fiction: Journalism and Imaginative Writing in America. Oxford: Oxford University Press.

Foley, Barbara (1986). Telling the Truth: The Theory and Practice of Documentary Fiction. Ithaca, NY: Cornell University Press.

Frus, Phyllis (1994). The Politics and Poetics of Journalistic Narrative: The Timely and the Timeless. Cambridge: Cambridge University Press.

Frye, Northrop (1971). The Anatomy of Criticism. Princeton, NJ: Princeton University Press.

Gutkind, Lee (2005). "The Creative Nonfiction Police.” B. Minh Nguyen and Porter Shreve, eds. Contemporary Creative Nonfiction: I \& Eye. New York: Pearson Longman, 349-54.

Hampl, Patricia (1999). I Could Tell You Stories: Sojourns in the Land of Memory. New York: Norton.

Hellman, John (1981). Fables of Fact: The New Journalism as New Fiction. Urbana, IL: University of Illinois Press.

Hersey, John (1980). "The Legend on the License." Yale Review 70, 1-25. 
Heyne, Eric (1987). "Toward a Theory of Literary Nonfiction.” Modern Fiction Studies 33.3, 479-90

Keene, Suzanne (2006). “A Theory of Narrative Empathy.” Narrative 14:3, 207-36.

Lehman, Daniel W. (1997). Matters of Fact: Reading Nonfiction Over the Edge. Columbus, OH: Ohio State University Press.

Martinich, A.P. and Avrum Stroll (2007). Much Ado About Nonexistence: Fiction and Reference. Lanham, MD: Rowman and Littlefield.

Nell, Victor (1988). Lost in a Book: The Psychology of Reading for Pleasure. New Haven, CT: Yale University Press.

Pavel, Thomas G. (1986). Fictional Worlds. Cambridge, MA: Harvard University Press.

Pearson, Michael (2005). “The Other Creative Writing.” Robert L. Root, Jr. and Michael Steinberg, eds. The Fourth Genre: Contemporary Writers of/on Creative Nonfiction. New York: Pearson, Longman, 366-70.

Phelan, James (1981). Worlds From Words: A Theory of Language in Fiction. Chicago, IL: Chicago University Press.

Ronen, Ruth (1994). Possible Worlds in Literary Theory. Cambridge: Cambridge University Press.

Ryan, Marie-Laure (1991). Possible Worlds, Artificial Intelligence, and Narrative Theory. Bloomington, IN: Indiana University Press.

Schank, Roger C. (1990). Tell Me a Story: A New Look at Real and Artificial Memory. New York: Charles Scribner's Sons.

Searle, John (1975). “The Logical Status of Fictional Discourse.” New Literary History 6, 319-32.

Smith, Barbara Herrnstein (1978). On the Margins of Discourse: The Relation of Literature to Language. Chicago, IL: University of Chicago Press.

Spence, Donald P. (1982). Narrative Truth and Historical Truth: Meaning and Interpretation in Psychoanalysis. New York: W.W. Norton.

Weber, Ronald (1980). The Literature of Fact: Literary Nonfiction in American Writing. Athens, OH: Ohio University Press.

White, Hayden (1987). The Content of the Form: Narrative Discourse and Historical Representation. Baltimore, MD: Johns Hopkins University Press.

Winterowd, W. Ross (1990). The Rhetoric of the 'Other' Literature. Carbondale, IL: Southern Illinois University Press.

Zavarzadeh, Mas'ud (1976). The Mythopoeic Reality: The Postwar American Nonfiction Novel. Urbana, IL: University of Illinois Press. 